\title{
Preliminary Investigation concerning Metals Bioavailability in Waters of Aries River Catchment by Using the Diffusive Gradients in Thin Films Technique
}

\author{
Marin Senila, Erika Andrea Levei, Lacrimioara Ramona Senila, and Marius Roman \\ INCDO-INOE 2000, Research Institute for Analytical Instrumentation, 67 Donath, 400293 Cluj-Napoca, Romania \\ Correspondence should be addressed to Erika Andrea Levei; erika.levei@icia.ro
}

Received 9 December 2014; Revised 20 February 2015; Accepted 6 March 2015

Academic Editor: Davide Vione

Copyright (c) 2015 Marin Senila et al. This is an open access article distributed under the Creative Commons Attribution License, which permits unrestricted use, distribution, and reproduction in any medium, provided the original work is properly cited.

\begin{abstract}
The paper presents the metals content and bioavailability in waters of Aries River catchment, Romania. Concentration of labile dissolved metal species measured by diffusive gradients in thin films technique (DGT), metals in colloidal and in particulate phases, and also general physical-chemical indicators of water were determined. Very high total metal concentrations were found in the tributaries that drain the mining areas. However, the influence of the polluted tributaries on the Aries River water quality was moderate, as a consequence of the tributaries low flow rate compared with that of the Aries River. Using the DGT technique the bioavailable metals fractions expressed as \% of total dissolved metals concentrations were found to be $28-88 \%$ for $\mathrm{Cu}, 43-72 \%$ for $\mathrm{Zn}, 73-85 \%$ for $\mathrm{Fe}$, and $33-70 \%$ for Mn. Depending on the used method for dissolved metals determination the classification of waters according to quality classes may differ. Excluding the colloidal metal fractions, DGT measures only truly dissolved metal concentrations. In cases with very high metal contamination the differences between total dissolved and DGT-labile concentrations are unimportant for waters classification. However, where the metals concentration is near the thresholds values the determination method is very important.
\end{abstract}

\section{Introduction}

Metals can enter in the aquatic environment via natural pathways, but the anthropogenic inputs can increase total metal concentrations above the values that may pose risks for biota $[1,2]$. Some elements (Cd, $\mathrm{Ni}, \mathrm{As}, \mathrm{Hg}$, etc.) are nonessential for aquatic organisms and have toxic effects even in very low concentrations, while others ( $\mathrm{Fe}, \mathrm{Mn}, \mathrm{Zn}, \mathrm{Cu}$, etc.) are essential but may become toxic in elevated concentrations. However, metals toxicity is influenced not only by their total concentration, but also by their bioavailability. Generally, the metals with the highest bioavailability are those found in labile or dissolved forms [3].

The accurate measurement of bioavailable metals concentration is often a difficult task considering that colloids containing metals can pass through $0.10-0.45 \mu \mathrm{m}$ filters (typically used for water samples filtration prior to the measurement of dissolved metal species), introducing positive errors in the determination of truly dissolved metal concentrations.
A relatively simple, but very efficient, measuring tool for the determination of truly dissolved metals in water is the diffusive gradients in thin films (DGT) technique that is based on the diffusion of labile metal species through a diffusive gel, according to their diffusion coefficients, followed by trapping in a resin gel that accumulates metals.

Devices used for DGT technique contain a layer of hydrogel and a layer of resin gel and function based on Fick's first law of diffusion [3]. If the transport of metal ions to the collecting resin is ensured exclusively by free diffusion through the diffusive layer, the concentration in the bulk solution can be calculated from the metal mass collected in the resin [4].

The DGT method is used for different purposes, including in situ measurements of labile trace metal species in surface waters and sediments, monitoring (time averaged concentrations), speciation (labile inorganic and/or organic species), and bioavailability assessment (effective concentration) $[4,5]$. Moreover, the DGT technique may be a candidate 
for assessing the environmental risk from a deep sea tailings outfall [6] and predicting metals toxicity in water [7]. Ferreira et al. [8] used DGT as surrogate of biomonitors to predict metals toxicity in waters. DGT was also used to measure the metal fluxes in sediments and soils [9] and to calculate the free ions and labile fractions of the metals for contaminated sites [10]. Zhang and collaborators [11] reported that DGT is an effective method to predict the accumulation of metals by plants and to assess the bioavailable fraction of metals in soils. Good correlations between bioavailable elements in soils and elements accumulated by plants were reported, following assessments by pot experiments and in field conditions [1214].

In practice, the DGT device is deployed for a fixed time in a water sample. At retrieval, the resin gel layer is peeled off and the mass of the accumulated ions in this layer is measured. The ions in the Chelex resin layer are eluted with a known volume of $1 \mathrm{M} \mathrm{HNO}_{3}$ solution. The concentrations of ions in the eluent are then measured by a spectrometric technique. The eluted to bound metal ratio is known as the elution factor, which has reported values of 0.8 [15].

The exploitation of precious and base metals reserves since pre-Roman times (>1000 B.C.) flourished during Roman Empire times (2nd century A.D.) and continued during the Middle Ages up to present days generating a longterm pollution of several areas [16]. Among them there is the Aries River catchment located in the Metaliferi Mountains, southern part of the Apuseni Mountains, within the so-called Golden Quadrangle where precious and nonferrous metals were mined in underground (Rosia Montana, Baia de Aries) and open pit mines (Rosia Poieni) [17]. Although mining activities are presently ceased, the pollution with metals still remains [17-20]. However, to the best of our knowledge, there are no studies on the metals bioavailability in Aries River water and its tributaries.

The main aims of this work were to evaluate the contamination level and metals fractionation and to investigate the effectiveness of the DGT technique for the assessment of bioavailable pool of metals in waters of Aries River and some of its tributaries that drain the mining areas. Water physical-chemical parameters $(\mathrm{pH}$, electrical conductivity (EC), dissolved organic carbon (DOC), total nitrogen $\left(\mathrm{N}_{\mathrm{t}}\right)$, ammonia $\left(\mathrm{NH}_{4}{ }^{+}\right)$, and major anions $\left(\mathrm{Cl}^{-}, \mathrm{NO}_{2}{ }^{-}, \mathrm{NO}_{3}{ }^{-}\right.$, $\mathrm{SO}_{4}{ }^{2-}$, and $\mathrm{PO}_{4}{ }^{3-}$ )) and metals in three different forms (labile species, colloids, and particulates) were determined. The fractionation study was conducted only for $\mathrm{Fe}, \mathrm{Cu}, \mathrm{Mn}$, and $\mathrm{Zn}$ because their concentrations in all three forms were above the limits of quantification in all the analyzed samples. DGT was used as metal fractionation technique for the first time in the study area.

\section{Materials and Methods}

2.1. Sampling. Waters were collected in September 2013 from eight sampling points situated on the Aries River and its most polluted tributaries (Figure 1). On site, $\mathrm{pH}$ and EC were measured by a multiparameter instrument (350i, WTW), while DGT devices were deployed for one day into the river water. Three types of water samples were collected: (i) nonfiltered samples for the determination of total concentration of metals; (ii) samples filtered on site through $0.45 \mu \mathrm{m}$ cellulose acetate filter, for DOC, anions, $\mathrm{N}_{\mathrm{t}}$, and ammonia determinations; and (iii) samples filtered on site through $0.45 \mu \mathrm{m}$ cellulose acetate filter and acidified by adding ultrapure $65 \%$ nitric acid to a $\mathrm{pH}<2$, for the determination of total dissolved metals concentrations.

2.2. Materials. All reagents used were of analytical grade. Ultrapure water from a Millipore (Molsheim, France) system was used for all dilutions. Ultrapure $\mathrm{HNO}_{3} 65 \%(\mathrm{~m} / \mathrm{m})$ (Merck, Germany) was used for acidification and digestion of water samples prior to metals determination. Stock multielement standard solutions of $1000 \mathrm{~g} \mathrm{~mL}^{-1}$ containing $\mathrm{Cu}$, $\mathrm{Zn}, \mathrm{Fe}$, and Mn (Merck, Germany) were used to calibrate the spectrometers for metals determination and stock multicomponent solutions of $1000 \mu \mathrm{g} \mathrm{mL}^{-1}$ containing $\mathrm{Cl}^{-}, \mathrm{NO}_{2}{ }^{-}$, $\mathrm{NO}_{3}{ }^{-}, \mathrm{SO}_{4}{ }^{2-}$, and $\mathrm{PO}_{4}{ }^{3-}$ (Merck, Germany) were used for ion chromatographic determinations.

DGT deployment units (purchased from DGT Research Ltd., Lanchester, UK) were used to measure labile metal species. A DGT device contains a plastic base $(2.5 \mathrm{~cm}$ diameter) loaded with resin gel, diffusive gel, and a filter covered by an outer sleeve to leave a $2.0 \mathrm{~cm}$ diameter window [15]. The used devices in our experiments contained a $4 \mathrm{~mm}$ thick layer of Chelex-100 ion-exchange resin; $8 \mathrm{~mm}$ thick diffusive gel DGT cross-linker with open pore (allylglycidylagarose); and $0.145 \mathrm{~mm}$ thick membrane filter. Syringes with mountable filter holders containing $0.45 \mu \mathrm{m}$ cellulose acetate filter purchased from Sartorius were used for on-site water filtration.

2.3. Instrumentation. Determinations of metals were carried out using two instruments, depending on the concentration levels: inductively coupled plasma atomic emission spectrometer, ICP-AES Optima 5300 DV (Perkin Elmer, Norwalk, USA), and inductively coupled plasma mass spectrometer ICP-MS ELAN DRC II (Perkin-Elmer, Toronto, Canada) equipped with a reaction cell for reducing the interferences. An OI Analytical Microwave digestion unit was used for samples digestion before total metals determination. Anions were analyzed directly in the filtered water by ion chromatography using the 761 Compact IC (Metrohm, Herisau, Switzerland). DOC and $\mathrm{N}_{\mathrm{t}}$ were measured using a 2100 Multi N/C analyzer (Analytic Jena, Jena, Germany) based on sample combustion followed by infrared detection of $\mathrm{CO}_{2}$ and chemiluminescence detection of NO. All the determinations were carried out in triplicate. The accuracy of metals determination was tested by analyzing NIST 1643e freshwater (National Institute of Standards and Technology (NIST), Canada), while that of anions was tested using the BCR 616 artificial groundwater certified reference sample (Institute for Reference Materials and Measurements (IRMM), Belgium). Recovery degrees ranged between 94 and 102\% for metals and 95 and 105\% for anions.

2.4. Measurement of Metals Fractions in Water. Total metal content was measured in the unfiltered samples, while 


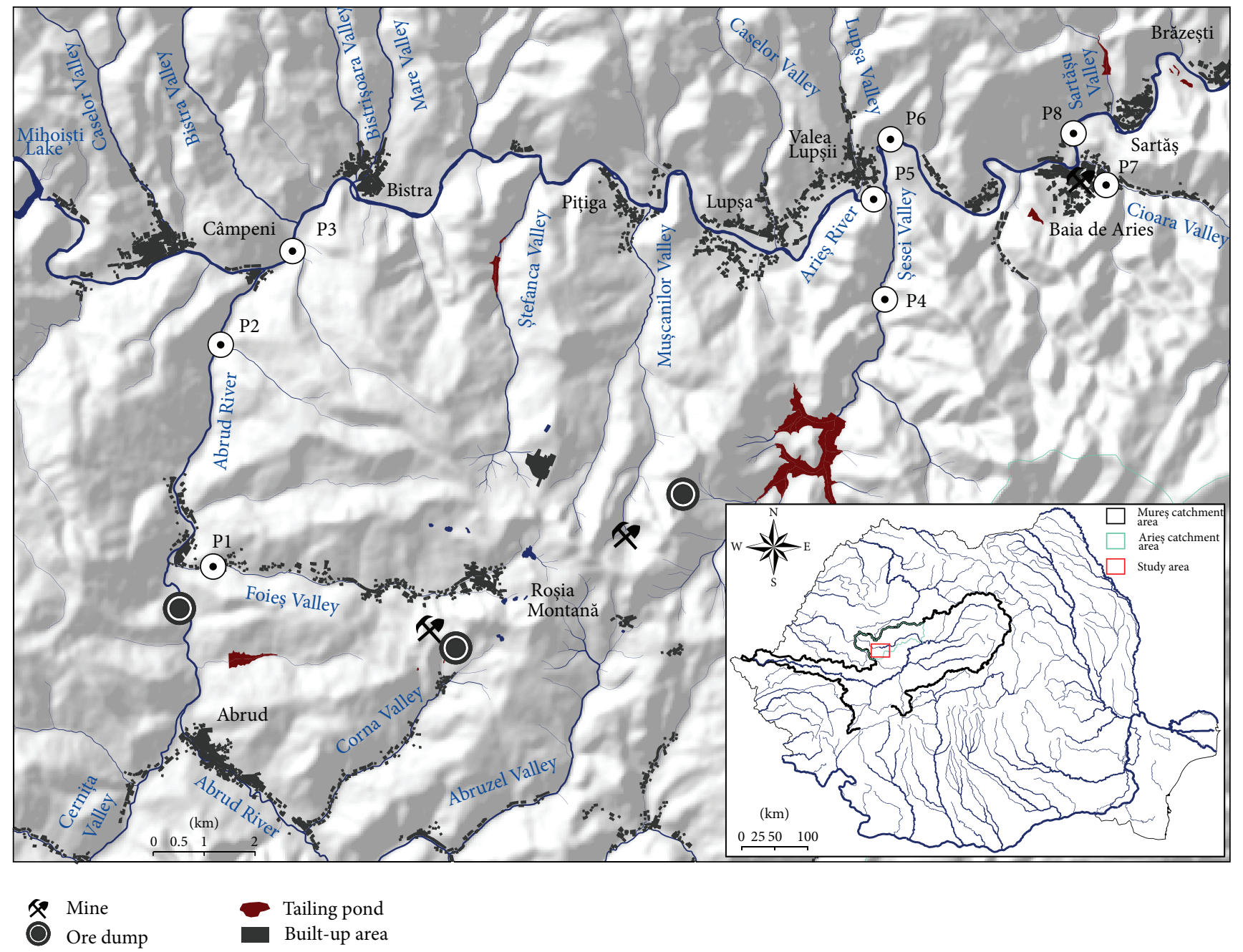

FIgURE 1: Aries River catchment, sampling stations, and mining sites.

the total dissolved metal contents were determined in the filtered acidulated samples. The DGT-labile metal species were measured by deploying the DGT devices in the river water. All the determinations were carried out in triplicate. After 24 hours, the devices were retrieved and carefully washed using distilled and ultrapure water and then the resins containing the retained metals were immersed for 24 hours in $5 \mathrm{~mL} 1 \mathrm{M} \mathrm{HNO}_{3}$ for metals elution.

Calculations of the DGT measured concentration are based on Fick's first law of diffusion [15]:

$$
F=D \frac{d C}{d x}
$$

where $F$ is steady state flux of an ion, $D$ is diffusion coefficient, and $d C / d x$ is concentration gradient.

After the measurement of metals in the eluted solution by spectrometric method, the mass of metal accumulated in the resin gel layer $(M)$ was calculated according to

$$
M=\frac{C_{e}\left(V_{g}+V_{e}\right)}{f_{e}}
$$

where $C_{e}$ is the concentration of metals in the $1 \mathrm{M} \mathrm{HNO}_{3}$ elution solutions (in $\mu \mathrm{g} \mathrm{L}^{-1}$ ), $V_{g}$ is the volume of the resin gel, typically $0.15 \mathrm{~mL}, V_{e}$ is the volume of $\mathrm{HNO}_{3}$ added to the resin gel $(0.5 \mathrm{~mL})$, and $f_{e}$ is the elution factor for each metal, typically 0.8 .

The concentration of metal measured by DGT $\left(C_{\mathrm{DGT}}\right)$ was calculated using

$$
C_{\text {DGT }}=\frac{M \Delta g}{D t A},
$$

where $\Delta g$ is the thickness of the diffusive gel $(0.8 \mathrm{~mm})$ plus the thickness of the filter membrane (typically $0.14 \mathrm{~mm}$ ), $D$ is the diffusion coefficient of metal in the gel, $t$ is deployment time, and $A$ is exposure area $\left(A=3.14 \mathrm{~cm}^{2}\right)$.

Labile metals concentrations were measured using the DGT technique and ICP-MS, with the exception of Fe which was measured by ICP-AES. The metals content in colloids was calculated as the difference between total dissolved metals and DGT-labile metals. The metals content in particulates was calculated as the difference between total metals and total dissolved metals in water. 


\section{Results and Discussions}

3.1. General Characteristics of Waters in Aries River and Its Tributaries. The physical-chemical parameters of waters are presented in Table 1 . According to Romanian regulations (OM 161, 2006) surface waters are classified in five quality classes in terms of their ecological status. The $\mathrm{pH}$ values were in the neutral range in the main stream of Aries River, with values ranging between 7.61 and 8.25 , but they were in the acidic range in waters from all analyzed tributaries (4.10 in P1, Foies stream; 4.23 in P2, Abrud rivulet; 4.54 in P4, Sesei rivulet; 5.63 in P7, mine water from Baia de Aries), due to strong contamination by acidic mine drainage waters. Due to the small flow rate of these effluents, the $\mathrm{pH}$ values of Aries River remain neutral even after their confluences. The values of EC in the main stream were in the range of $234-361 \mu \mathrm{S} \mathrm{cm}^{-1}$, while in effluents they were generally one order of magnitude higher $\left(1160-2440 \mu \mathrm{S} \mathrm{cm}^{-1}\right)$. The values of measured DOC ranged between 1.52 and $5.80 \mathrm{mg} \mathrm{L}^{-1}$, with the highest values in samples P1 (stream Foies, tributary of Abrud) and P2 (Abrud, tributary of Aries River).

The $\mathrm{N}_{\mathrm{t}}$ concentration corresponds to class I $\left(<1.5 \mathrm{mg} \mathrm{L}^{-1}\right)$ in the majority of the samples, although in Foies and Abrud effluents the total nitrogen concentration slightly exceeds that value and thus corresponds to class II (1.5-7 $\left.\mathrm{mg} \mathrm{L}^{-1}\right)$.

The concentrations of chloride in the water of the Aries River and tributaries corresponded to class I (very good quality) ( $<25 \mathrm{mg} \mathrm{L}^{-1}$ ), those of nitrites corresponded to class I except for P1 and P2 where they corresponded to class III (fair) (0.06-0.3 $\left.\mathrm{mg} \mathrm{L}^{-1}\right)$, those of nitrates corresponded to class I (very good) in all analyzed samples $\left(<1 \mathrm{mg} \mathrm{L}^{-1}\right)$, while those of ammonium corresponded to class I (very good quality) $\left(<0.4 \mathrm{mg} \mathrm{L}^{-1}\right)$ except for P1 and P2 where they corresponded to class III (fair) $\left(1.3-3.2 \mathrm{mg} \mathrm{L}^{-1}\right)$. These values show a moderate to low contamination of water with pollutants upcoming from domestic activities (domestic animal residues, fertilizers used in agriculture, domestic wastes, etc.).

Sulfates generally show a contribution of mining activities to pollution, and they ranged between 22.6 and $105 \mathrm{mg} \mathrm{L}^{-1}$ in Aries River which match to classes I and II but were much higher in the tributaries, with values corresponding to class III (250-300 $\mathrm{mg} \mathrm{L}^{-1}$ ) in P1 and P2 and to class $\mathrm{V}$ (very poor quality) (>300 $\mathrm{mg} \mathrm{L}^{-1}$ ) in Sesei rivulet (P4) and mine water in Baia de Aries (P7).

3.2. Concentrations of Dissolved Metals, Metals in Colloids, and Metals in Particulate. The accuracy of the DGT technique was verified in the laboratory using a synthetic solution with $0.2 \mu \mathrm{gL}^{-1}$ from each metal ( $\mathrm{Cu}, \mathrm{Zn}, \mathrm{Fe}$, and $\mathrm{Mn}$ ). Recoveries of the measured concentrations, compared to the theoretical value of $0.2 \mu \mathrm{g} \mathrm{L}^{-1}$, ranged between $86 \%$ and $110 \%$ for all analyzed metals, showing good accuracy of the method [21].

The obtained results for DGT-labile metals and total dissolved and total metals concentrations are presented in Table 2.
Very high total concentrations of $\mathrm{Mn}, \mathrm{Fe}, \mathrm{Zn}$, and $\mathrm{Cu}$ were found in waters of all tributaries which clearly indicate an input of acid mine drainage (AMD) from mining-affected sites.

Total $\mathrm{Zn}$ concentrations were over $2000 \mu \mathrm{g} \mathrm{L}-1$ in waters of tributaries, while in Aries River they ranged between 238 and $461 \mu \mathrm{gL}^{-1}$. Only a small part of the total $\mathrm{Zn}$ concentration was found in DGT-labile form $(<10 \%)$, while important quantities were in particulates. Even so, the DGTlabile $\mathrm{Zn}$ indicates a poor quality of water in tributaries. The highest value of total Fe concentration $\left(2220 \mu \mathrm{gL}^{-1}\right)$ was found in Sesei rivulet, but high total Fe was also found in the other tributaries. In Aries River main stream the total Fe concentrations were between 225 and $340 \mu \mathrm{g} \mathrm{L}^{-1}$. Total $\mathrm{Cu}$ concentration was much higher in the Sesei rivulet $\left(2010 \mu \mathrm{g} \mathrm{L}^{-1}\right)$ than in all the other analysed samples. In the main stream of Aries River, the total concentrations of $\mathrm{Cu}$ were in the range of $34-55 \mu \mathrm{g} \mathrm{L}^{-1}$. DGT-labile $\mathrm{Cu}$ concentrations were $7.5-466 \mu \mathrm{g} \mathrm{L}^{-1}$ (highest value in Sesei rivulet). Total $\mathrm{Mn}$ concentrations were $316-5350 \mu \mathrm{g} \mathrm{L}^{-1}$, of which $32.1-566 \mu \mathrm{g} \mathrm{L}^{-1}$ was found in DGT-labile forms. The highest Mn concentration was found, as in the case of the other analysed metals, in Sesei rivulet $\left(5350 \mu \mathrm{g} \mathrm{L}^{-1}\right)$.

According to Romanian water quality standards (OM 161, 2006) the dissolved concentrations of metals are required to assess the quality of surface waters. Conventionally, dissolved concentration is measured after sample filtration using $0.45 \mu \mathrm{m}$ pore-filters. As defined in our case, this is equivalent to "total dissolved" concentration. Considering the total dissolved concentrations of metals the water of the Aries River (P3, P5, P6, and P8) corresponded to class II (good quality), due to the $\mathrm{Mn}$ concentrations (50-100 $\left.\mu \mathrm{g} \mathrm{L}^{-1}\right)$. In contrast, by considering labile concentrations measured by DGT, the water status corresponded to class I (very good quality), for all analyzed metals. However, in tributaries, metal concentrations were much higher. The water quality in Sesei tributary corresponds to class V (bad status) if the total dissolved $\mathrm{Cu}\left(250 \mu \mathrm{g} \mathrm{L}^{-1}\right)$ and $\mathrm{Mn}\left(1000 \mu \mathrm{g} \mathrm{L}^{-1}\right)$ concentrations are considered. If DGT-labile $\mathrm{Cu}$ concentration is considered, the water in this tributary also corresponded to class V. The water in the other three tributaries (P1, P2, and $\mathrm{P} 7$ ) is generally less contaminated than in the Sesei rivulet but due to the total dissolved concentrations of Mn water in P1 and P7 corresponded to class III (fair). If it is considered the total dissolved concentrations of $\mathrm{Mn}$ and $\mathrm{Zn}$, water quality in P2 corresponds to class II (good quality). If DGT-labile Mn concentration is considered, the water in P1 can be considered as having a good status (class II).

Therefore, depending on the used method for dissolved metals determination the classification of waters according to quality classes may differ. Excluding the colloidal metal fractions, DGT accumulates only truly dissolved metal concentrations. In cases with very high metal contamination the differences between total dissolved and DGT-labile concentrations are unimportant for waters classification. However, in particular cases where the metals concentration is near the thresholds values the determination method is very important. 


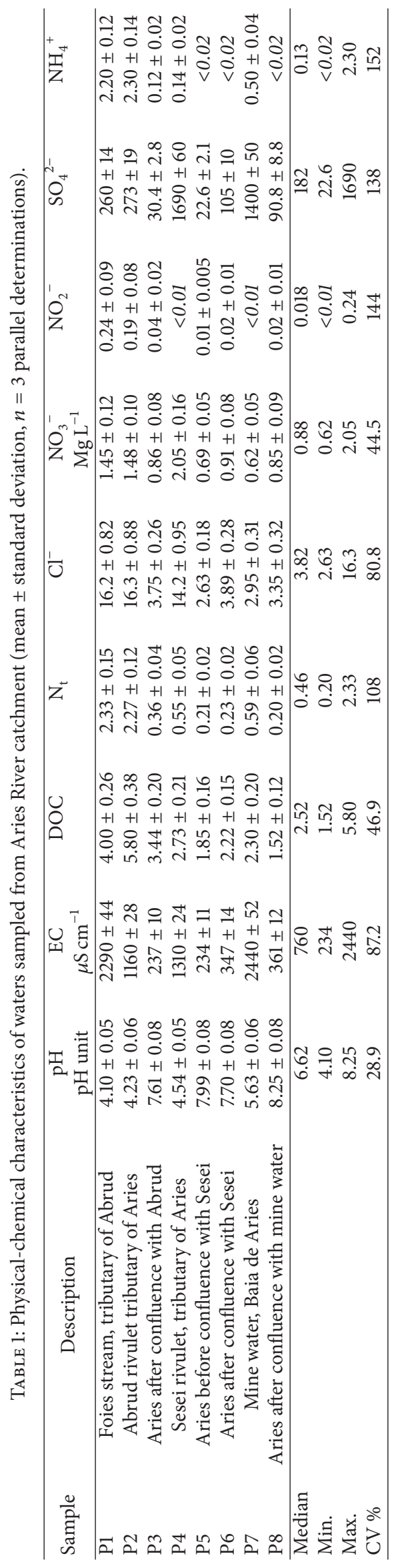


TABLE 2: Concentrations of DGT-labile and total dissolved and total metal concentrations $\left(\mu \mathrm{g} \mathrm{L}^{-1}\right.$, mean \pm standard deviation, $n=3$ parallel determinations).

\begin{tabular}{|c|c|c|c|c|c|c|c|c|}
\hline Sample & P1 & $\mathrm{P} 2$ & P3 & $\mathrm{P} 4$ & P5 & P6 & P7 & P8 \\
\hline \multicolumn{9}{|c|}{$\mathrm{Zn}$} \\
\hline DGT $^{*}$ & $250 \pm 20$ & $239 \pm 19$ & $33.5 \pm 3.1$ & $299 \pm 31$ & $29.0 \pm 2.3$ & $33.0 \pm 3.3$ & $201 \pm 18$ & $24.0 \pm 2.2$ \\
\hline tot dis* & $367 \pm 11$ & $364 \pm 14$ & $51.4 \pm 1.8$ & $416 \pm 12$ & $67.5 \pm 4.1$ & $46.3 \pm 1.2$ & $326 \pm 12$ & $38.2 \pm 1.3$ \\
\hline total $^{*}$ & $2200 \pm 90$ & $2180 \pm 81$ & $461 \pm 22$ & $3550 \pm 95$ & $279 \pm 12$ & $383 \pm 19$ & $2320 \pm 78$ & $238 \pm 10$ \\
\hline \multicolumn{9}{|c|}{$\mathrm{Fe}$} \\
\hline DGT & $225 \pm 21$ & $236 \pm 18$ & $93.0 \pm 8.0$ & $620 \pm 28$ & $55.1 \pm 4.2$ & $53.0 \pm 4.4$ & $203 \pm 20$ & $82.1 \pm 8.1$ \\
\hline tot dis & $265 \pm 4.2$ & $288 \pm 5.3$ & $124 \pm 3.3$ & $811 \pm 20$ & $75.0 \pm 2.0$ & $69.2 \pm 1.4$ & $250 \pm 3.3$ & $99.0 \pm 2.0$ \\
\hline total & $1020 \pm 31$ & $935 \pm 28$ & $340 \pm 12$ & $2220 \pm 44$ & $225 \pm 11$ & $280 \pm 11$ & $690 \pm 18$ & $301 \pm 13$ \\
\hline \multicolumn{9}{|c|}{$\mathrm{Cu}$} \\
\hline DGT & $26.2 \pm 2.2$ & $19.0 \pm 2.0$ & $7.5 \pm 0.8$ & $466 \pm 51$ & $8.7 \pm 1.0$ & $11.2 \pm 1.1$ & $134 \pm 12$ & $10.1 \pm 1.0$ \\
\hline tot dis & $94.1 \pm 5.0$ & $22.1 \pm 0.3$ & $11.0 \pm 0.4$ & $850 \pm 40$ & $9.8 \pm 0.2$ & $14.1 \pm 0.3$ & $226 \pm 8.2$ & $14.0 \pm 0.4$ \\
\hline total & $182 \pm 4.3$ & $123 \pm 5.1$ & $34.0 \pm 2.0$ & $2010 \pm 62$ & $42.0 \pm 2.1$ & $36.0 \pm 2.0$ & $340 \pm 8.6$ & $55.1 \pm 3.3$ \\
\hline \multicolumn{9}{|c|}{$\mathrm{Mn}$} \\
\hline DGT & $178 \pm 18$ & $99.0 \pm 8.6$ & $32.3 \pm 20$ & $566 \pm 20$ & $38.2 \pm 3.3$ & $32.1 \pm 3.2$ & $326 \pm 28$ & $40.2 \pm 3.9$ \\
\hline tot dis & $306 \pm 13$ & $232 \pm 13$ & $46.0 \pm 1.4$ & $2080 \pm 88$ & $60.2 \pm 2.4$ & $98.0 \pm 5.8$ & $590 \pm 23$ & $88.0 \pm 4.4$ \\
\hline total & $1220 \pm 45$ & $936 \pm 42$ & $350 \pm 12$ & $5350 \pm 96$ & $316 \pm 12$ & $456 \pm 24$ & $3300 \pm 88$ & $415 \pm 17$ \\
\hline
\end{tabular}

${ }^{*}$ DGT: DGT-labile concentrations; tot dis: total dissolved (filtered by $0.45 \mu \mathrm{m}$ filters); total: total metal concentration in unfiltered samples.

The water quality in the main watercourse of Aries River was only slightly influenced by the poor water quality of tributaries, as the metals concentration in all forms (total, total dissolved, or DGT-labile) remains almost unchanged after the confluence with the polluted tributaries, mainly due to the low flow rate of the tributaries themselves.

The total dissolved concentrations of metals were in the same order of magnitude as those reported by Levei et al. [22] in 2009 on Aries River, but one order magnitude lower than those from Certej catchment, situated in the same mining area [23].

Distribution of $\mathrm{Cu}, \mathrm{Zn}, \mathrm{Fe}$, and $\mathrm{Mn}$ in the three main fractions (DGT-labile, colloidal, and particulate) expressed as $\%$ of the total metal content is presented in Figures 2(a), 2(b), 2(c), and 2(d).

As shown in Figure 2, in case of Cu DGT-labile concentrations represent between 14 and $40 \%$ of the total concentrations. The $\mathrm{Cu}$ fraction in colloids is between 2.5 and $37 \%$, while in particulates it is between 34 and $82 \%$. DGT-labile $\mathrm{Zn}$ represents about $7-11 \%$, the colloidal range represents between 3 and 14\%, while particulates contained about 76$89 \%$ of total $\mathrm{Zn}$. In case of $\mathrm{Fe}$, about $20-30 \%$ of total metal contents were in DGT-labile forms, $4-9 \%$ in colloids, and about $60-75 \%$ in particulates. In case of $\mathrm{Mn}$ the distribution of the three fractions was $7-15 \%$ in the dissolved phase, $4-15 \%$ in colloids, and $61-87 \%$ in particulates.

In a study conducted in several Japanese river waters, Han and collaborators [24] reported higher percent of dissolved $\mathrm{Cu}$ and $\mathrm{Zn}(>63.7 \%$ and $>86.1 \%$, resp.) than in our case. This can be explained by high amounts of particulates in water of Aries River and its tributaries, and these particulates contain an important fraction of the metals. In the same study, the authors reported a ratio of DGT-labile fractions to total dissolved fractions of $12-28 \%$ for $\mathrm{Cu}$ and $59-70 \%$ for
Zn. In our case DGT-labile fractions were $28-88 \%$ of total dissolved fractions for $\mathrm{Cu}, 43-72 \%$ for $\mathrm{Zn}, 73-85 \%$ for $\mathrm{Fe}$, and $33-70 \%$ for $\mathrm{Mn}$. The decrease of bioavailable metal species can be caused mainly by the metal-DOC complexation [25]. Metal-to-DOC ratios were calculated as $[\mathrm{M}] /[\mathrm{DOC}]$. The highest metal-to-DOC ratios were observed for Fe and $\mathrm{Mn}$ (because of high metal concentrations). However, no clear relationship between metal-to-DOC ratio and metal DGTlabile fraction was observed. DGT-labile fractions in total dissolved fractions were generally in the same order of magnitude for all the analyzed metals. This can be explained by very heterogeneous values of $\mathrm{pH}$ in the analyzed samples and by the influence of $\mathrm{pH}$ on the M-DOC equilibrium. Considering the low number of samples with similar $\mathrm{pH}$ from the main river watercourse a specific relationship between DOC and metals is difficult to determine.

\section{Conclusions}

The metal contamination level in Aries River and its miningimpacted tributaries was evaluated. Generally, the physicalchemical parameters indicated the water contamination by mining activities. In the studied tributaries of Aries the values of $\mathrm{pH}$ were in the acidic range and EC showed increased values. Waters of tributaries contain also high concentrations of sulfates, which can indicate contamination by mining activities. In contrast, the detected contents of chlorides, phosphates, and nitrogen (nitrites, nitrates, and ammonia) were low, indicating that domestic activities did not significantly contribute to water pollution in this catchment. Metals ( $\mathrm{Fe}, \mathrm{Zn}, \mathrm{Cu}$, and $\mathrm{Mn}$ ) concentrations were higher in tributaries. The results showed that labile concentrations of metals measured by DGT are lower than total dissolved metals analyzed after filtration with $0.45 \mu \mathrm{m}$ filters. Despite 


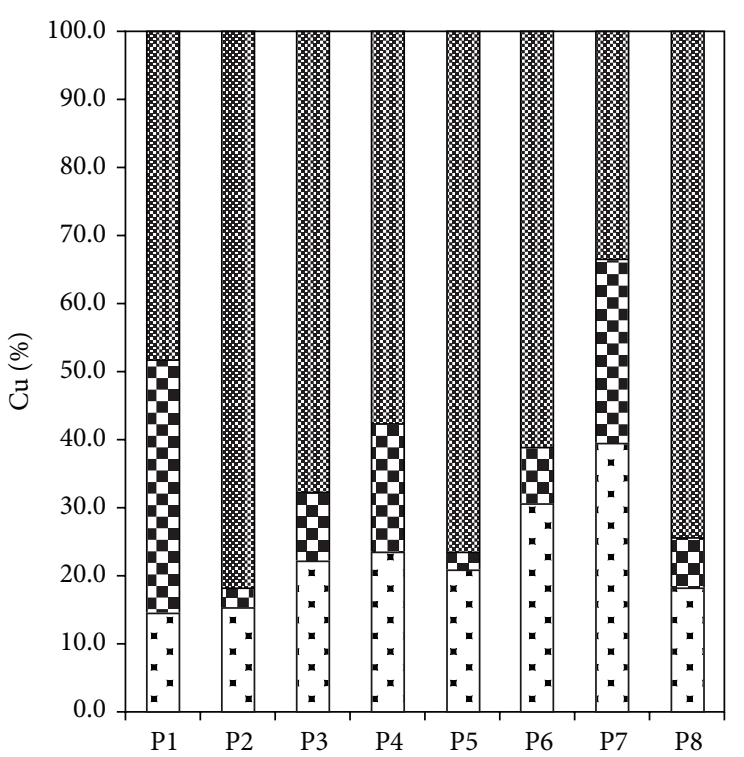

(a)

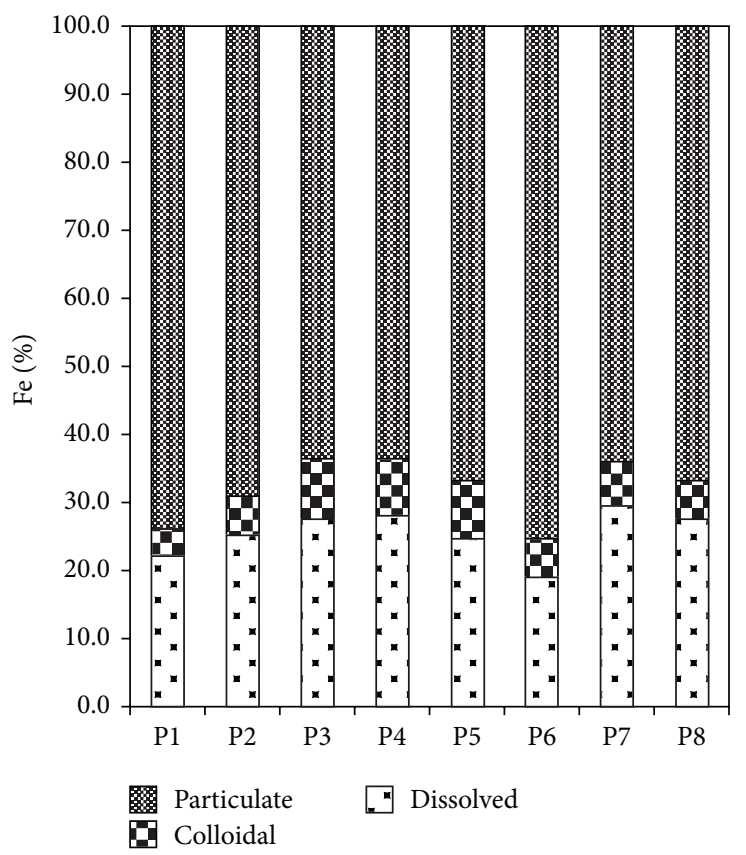

(c)

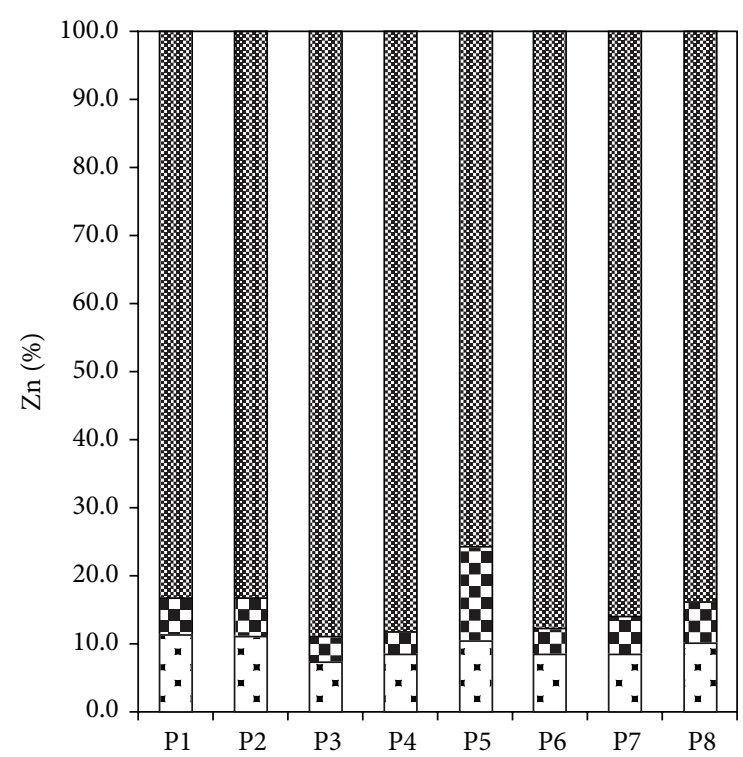

(b)

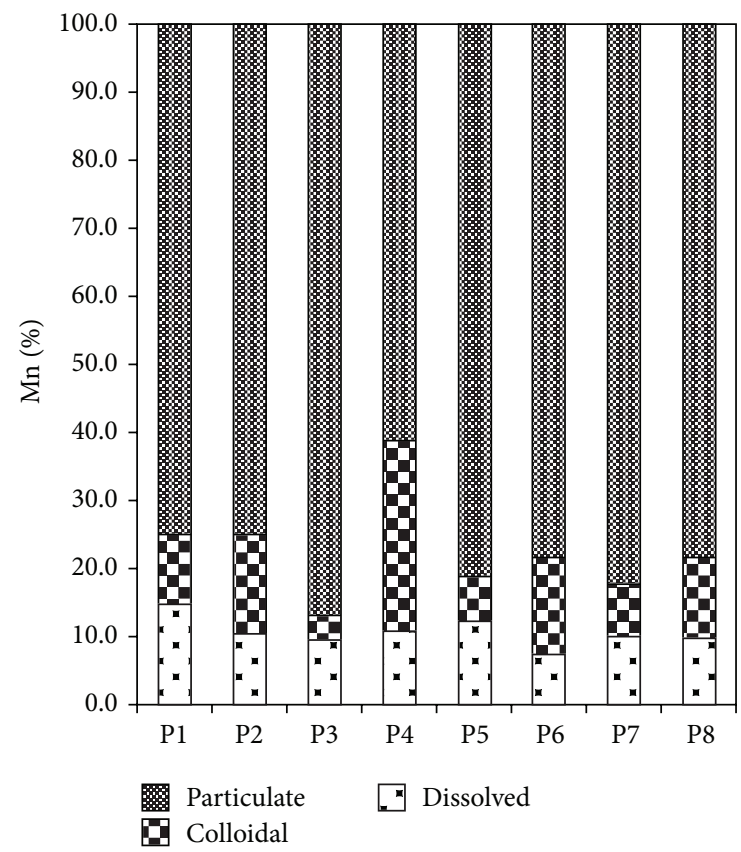

(d)

FIGURE 2: Metals distribution (\% of the total elements concentration) in DGT-labile fraction, in colloids, and in particulates in Aries River and tributaries (dis: dissolved (DGT-labile)); col: colloidal (total dissolved - DGT-labile); part: particulate (total - total dissolved (0.45 $\mu \mathrm{m})$ ).

the significant metal inputs and the acidic $\mathrm{pH}$ of the tributaries that drain the mining areas, the increase of the metals' concentrations in the Aries River was moderate, while the $\mathrm{pH}$ was not significantly affected. This is probably due to the dilution effect that occurs as a result of the low flow rate of the tributaries compared with the Aries River. However, high metal loads of tributaries are of concern. The obtained results can be used by various stakeholders in order to take adequate measures to reduce sources of pollution.

Overall, the DGT technique has been found to be an effective method for in situ fractionation of trace metals in aqueous samples of Aries River catchment, a mining-affected area. Nevertheless, future work is needed by collecting a larger number of samples in order to find relationships between metals bioavailability and other water physicalchemical characteristics.

\section{Conflict of Interests}

Marin Senila declares that he has no conflict of interests. Erika Andrea Levei declares that she has no conflict of interests. 
Lacrimioara Ramona Senila declares that she has no conflict of interests. Marius Roman declares that he has no conflict of interests.

\section{Acknowledgment}

This work was supported by Romanian Financing Authority CNCS-UEFISCDI, Partnership, Project VULMIN, Contract no. $52 / 2012$.

\section{References}

[1] P. Bradac, B. Wagner, D. Kistler, J. Traber, R. Behra, and L. Sigg, "Cadmium speciation and accumulation in periphyton in a small stream with dynamic concentration variations," Environmental Pollution, vol. 158, no. 3, pp. 641-648, 2010.

[2] M. Şenilă, E. A. Levei, L. R. Şenilă, G. M. Oprea, and C. M. Roman, "Mercury in soil and perennial plants in a miningaffected urban area from Northwestern Romania," Journal of Environmental Science and Health, Part A: Toxic/Hazardous Substances and Environmental Engineering, vol. 47, no. 4, pp. 614-621, 2012.

[3] N. Odzak, D. Kistler, H. Xue, and L. Sigg, "In situ trace metal speciation in a eutrophic lake using the technique of diffusion gradients in thin films (DGT)," Aquatic Sciences, vol. 64, no. 3, pp. 292-299, 2002.

[4] W. Davison and H. Zhang, "In situ speciation measurements of trace components in natural waters using thin-film gels," Nature, vol. 367, no. 6463, pp. 546-548, 1994.

[5] M. Pesavento, G. Alberti, and R. Biesuz, "Analytical methods for determination of free metal ion concentration, labile species fraction and metal complexation capacity of environmental waters: a review," Analytica Chimica Acta, vol. 631, no. 2, pp. 129141, 2009.

[6] J. E. Sherwood, D. Barnett, N. W. Barnett et al., "Deployment of DGT units in marine waters to assess the environmental risk from a deep sea tailings outfall," Analytica Chimica Acta, vol. 652, no. 1-2, pp. 215-223, 2009.

[7] N. M. E. Deleebeeck, F. de Laender, V. A. Chepurnov, W. Vyverman, C. R. Janssen, and K. A. C. de Schamphelaere, "A single bioavailability model can accurately predict Ni toxicity to green microalgae in soft and hard surface waters," Water Research, vol. 43, no. 7, pp. 1935-1947, 2009.

[8] D. Ferreira, P. Ciffroy, M.-H. Tusseau-Vuillemin, A. Bourgeault, and J.-M. Garnier, "DGT as surrogate of biomonitors for predicting the bioavailability of copper in freshwaters: an ex situ validation study," Chemosphere, vol. 91, no. 3, pp. 241-247, 2013.

[9] H. G. van der Geest and M. L. Paumen, "Dynamics of metal availability and toxicity in historically polluted floodplain sediments," Science of the Total Environment, vol. 406, no. 3, pp. 419-425, 2008.

[10] M. L. Ruello, M. Sileno, D. Sani, and G. Fava, "DGT use in contaminated site characterization. The importance of heavy metal site specific behaviour," Chemosphere, vol. 70, no. 6, pp. 1135-1140, 2008.

[11] H. Zhang, F.-J. Zhao, B. Sun, W. Davison, and S. P. Mcgrath, "A new method to measure effective soil solution concentration predicts $\mathrm{Cu}$ availability to plants," Environmental Science \& Technology, vol. 35, no. 12, pp. 2602-2607, 2001.

[12] C. Zhang, S. Ding, D. Xu, Y. Tang, and M. H. Wong, "Bioavailability assessment of phosphorus and metals in soils and sediments: a review of diffusive gradients in thin films (DGT)," Environmental Monitoring and Assessment, vol. 186, no. 11, pp. 7367-7378, 2014.

[13] M. Senila, E. A. Levei, and L. R. Senila, "Assessment of metals bioavailability to vegetables under field conditions using DGT, single extractions and multivariate statistics," Chemistry Central Journal, vol. 6, no. 1, article 119, 2012.

[14] M. Senila, "Real and simulated bioavailability of lead in contaminated and uncontaminated soils," Journal of Environmental Health Science and Engineering, vol. 12, no. 1, p. 108, 2014.

[15] DGT-for Measurements in Waters, Soils and Sediments, DGT Research Ltd, Lancaster, UK, 2013, http://www.dgtresearch .com/.

[16] C. G. Tămaş, L. Bailly, L. Ghergari, G. O’Connor, and A. Minuţ, "New occurrences of tellurides and argyrodite in Roşia Montana Apuseni Mountains, Romania, and their metallogenic significance," The Canadian Mineralogist, vol. 44, no. 2, pp. 367383, 2006.

[17] M. Sima, B. Dold, L. Frei, M. Senila, D. Balteanu, and J. Zobrist, "Sulfide oxidation and acid mine drainage formation within two active tailings impoundments in the Golden Quadrangle of the Apuseni Mountains, Romania," Journal of Hazardous Materials, vol. 189, no. 3, pp. 624-639, 2011.

[18] G. Bird, P. A. Brewer, M. G. Macklin, M. Serban, D. Balteanu, and B. Driga, "Heavy metal contamination in the Arieş river catchment, western Romania: implications for development of the Roşia Montana gold deposit," Journal of Geochemical Exploration, vol. 86, no. 1, pp. 26-48, 2005.

[19] C. Marin, A. Tudorache, O. T. Moldovan, I. Povara, and G. Rajka, "Assessing the contents of arsenic and of some heavy metals in surface flows and in the hyporheic zone of the aries stream catchment area, Romania," Carpathian Journal of Earth and Environmental Sciences, vol. 5, no. 1, pp. 13-24, 2010.

[20] E. Levei, M. Ponta, M. Senila, M. Miclean, and T. Frentiu, "Assessment of contamination and origin of metals in mining affected river sediments: a case study of the Aries River catchment, Romania," Journal of the Serbian Chemical Society, vol. 79, no. 8, pp. 1019-1036, 2014.

[21] A. Drolc and A. Pintar, "Method validation and measurement uncertainty evaluation for measurement of mass concentration of organic acids in fermentation broths by using ion chromatography," Accreditation and Quality Assurance, vol. 17, no. 3, pp. 323-330, 2012.

[22] E. Levei, M. Senila, M. Miclean et al., "Influence of rosia poieni and rosia montana mining areas on the water quality of the Aries River," Environmental Engineering and Management Journal, vol. 10, no. 1, pp. 23-29, 2011.

[23] J. Zobrist, M. Sima, D. Dogaru et al., "Environmental and socioeconomic assessment of impacts by mining activities-a case study in the Certej River catchment, Western Carpathians, Romania," Environmental Science and Pollution Research, vol. 16, pp. S14-S26, 2009.

[24] S. Han, W. Naito, Y. Hanai, and S. Masunaga, "Evaluation of trace metals bioavailability in Japanese river waters using DGT and a chemical equilibrium model," Water Research, vol. 47, no. 14, pp. 4880-4892, 2013.

[25] T. Yapici, I. I. Fasfous, J. Murimboh, and C. L. Chakrabarti, "Investigation of DGT as a metal speciation technique for municipal wastes and aqueous mine effluents," Analytica Chimica Acta, vol. 622, no. 1-2, pp. 70-76, 2008. 

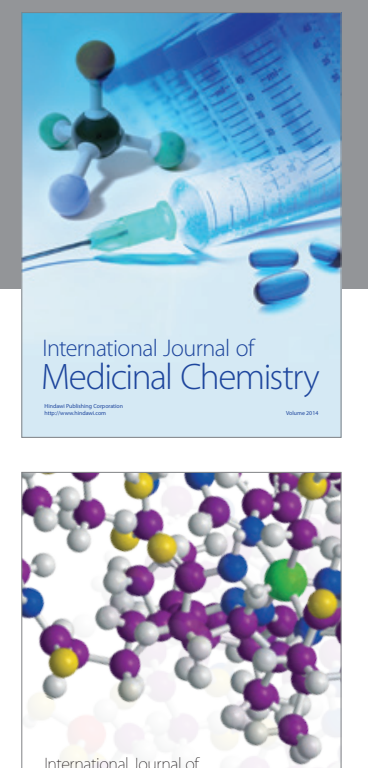

\section{Carbohydrate} Chemistry

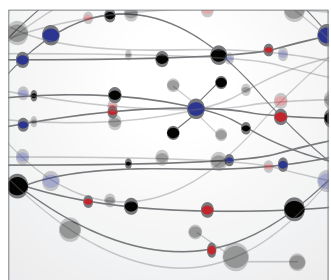

The Scientific World Journal
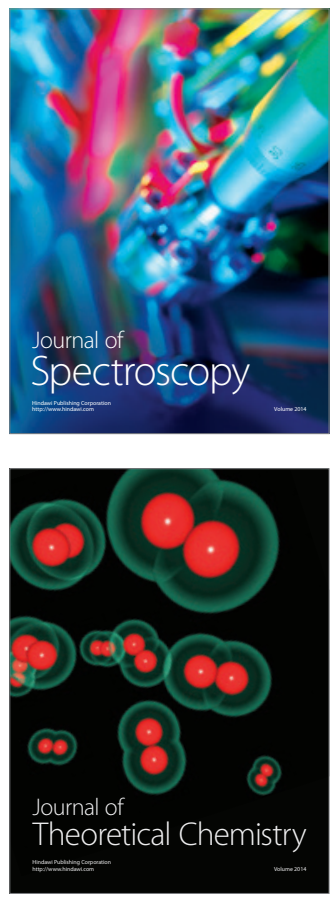
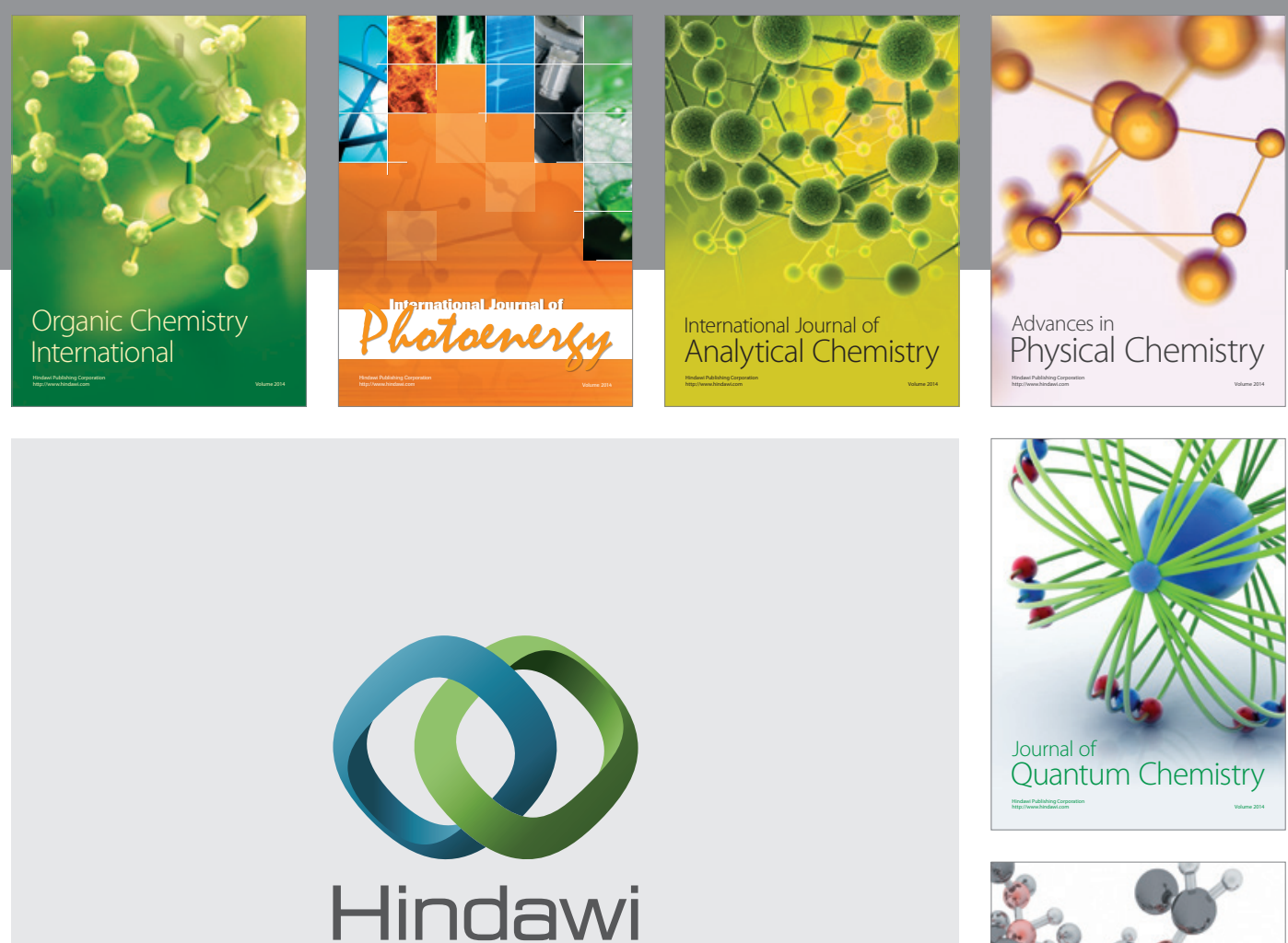

Submit your manuscripts at

http://www.hindawi.com

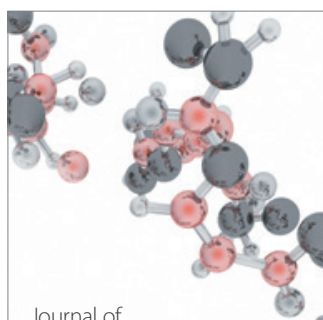

Analytical Methods

in Chemistry

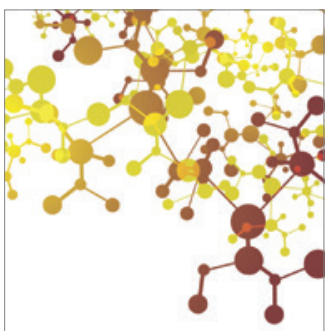

Journal of

Applied Chemistry

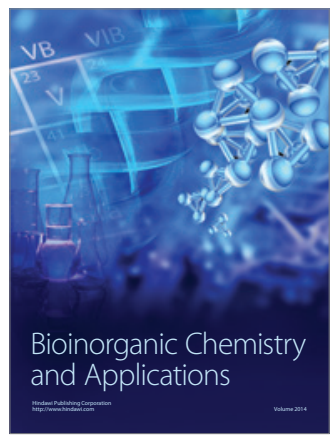

Inorganic Chemistry
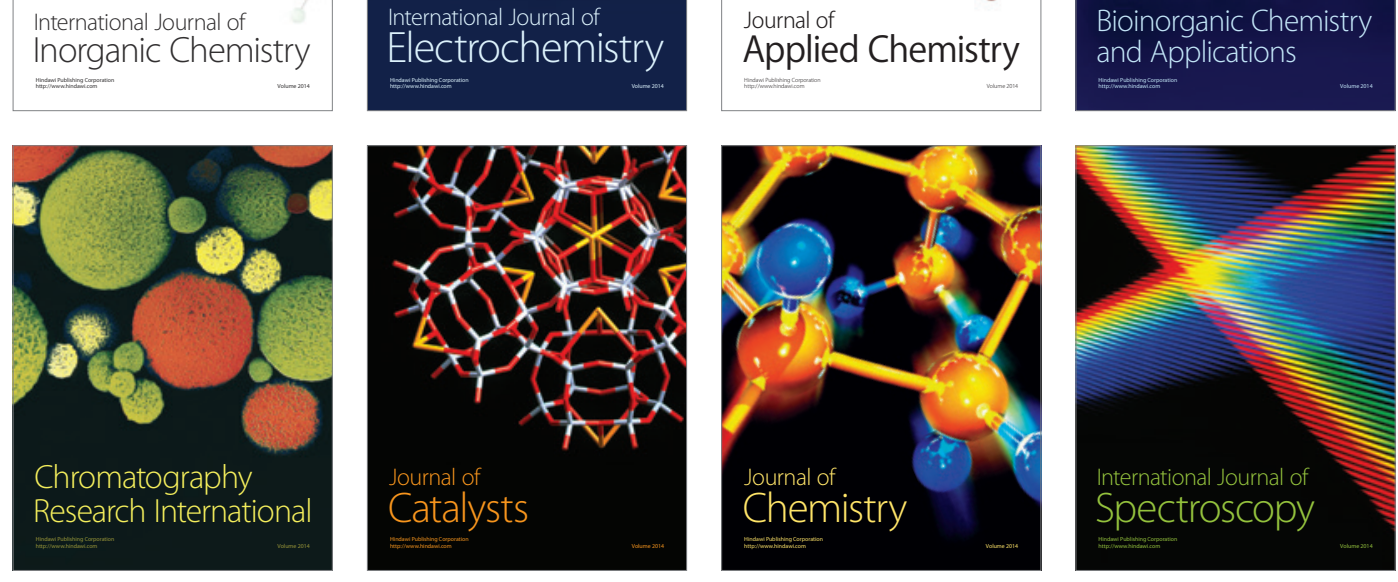